\title{
Educational Video Increases Maternal Self-Efficacy for Prevention of Diarrhoea in Young Children: A Randomised Clinical Trial
}

\author{
Emanuella Silva Joventino' ${ }^{1}$, Ádria Marcela Vieira Ferreira1, \\ Maria de Fátima Pereira de Sousa ${ }^{1}$, Jardeliny Corrêa da Penha ${ }^{1}$, \\ Mônica Oliveira Batista Oriá ${ }^{1}$, Paulo César de Almeida ${ }^{2}$, Lorena Barbosa Ximenes ${ }^{1}$ \\ ${ }^{1}$ Department of Nursing, Federal University of Ceará, Fortaleza, Brazil \\ ${ }^{2}$ University of the State of Ceará, Fortaleza, Brazil \\ Email: manujoventino@yahoo.com.br
}

Received 5 October 2014; revised 22 November 2014; accepted 7 December 2014

Copyright (C) 2014 by authors and Scientific Research Publishing Inc.

This work is licensed under the Creative Commons Attribution International License (CC BY). http://creativecommons.org/licenses/by/4.0/

(c) (i) Open Access

\begin{abstract}
The aim of this study was to compare the scores of maternal self-efficacy for child diarrhoea prevention, between intervention and control groups, according to sanitary, social and demographic characteristics. A randomised clinical trial was carried out on 163 mothers of children under 5 years old. Data collection was conducted during two months, at two different moments (M0 and M1); at the moment M0 only the intervention group watched the educational video to promote self-efficacy for child diarrhoea prevention; at M1 (two months later) the scale was applied to both groups. In the intervention group, greater mean self-efficacy scores were obtained compared with the control group. The following variables showed statistically significant associations $(p<0.05)$ with maternal self-efficacy: age 35 or over; high school education; working outside the home; residence with 4 to 5 people; house not of brick or mortar; public refuse collection; piped water supply; consumption of mineral water; and public sewerage network. After use of the video "Diarrhoea: you can prevent it", the maternal self-efficacy increased, proving that this strategy is able to assist the nursing staff in educational practices.
\end{abstract}

\section{Keywords}

Health Education, Diarrhoea, Infantile, Maternal Behaviour, Randomised Controlled Trial

\section{Introduction}

Despite the fact that it can be avoided, diarrhoea among young children has the demerit of being the second 
largest cause of death among children under five years old (yo), corresponding to 1.5 million deaths every year in the world [1]. This happens because the ailment persists as an infection which is hard to control, as it has a wide range of determining factors [2]. These factors refer mainly to environmental, social and economic issues, as the lack or shortage of sanitation services, and also the precarious housing conditions, which have had an effect on the occurrence of diarrhoea among young children, so as to increase the risk of affliction with diarrhea fifteenfold when compared to people living in adequate conditions of housing and sanitation [3].

Seeking to bring down these figures, and also considering the determining factors, we understand that the prevention and tackling of diarrhoea require the involvement of different segments of civil society and also of the government in the development and adoption of strategies. Among these practices, health education has stood out as a strategy to promote health, with an emphasis on the role of the nurse, as this professional has the sensitivity of making the care and education process coherent with the reality of each segment of the population, with a view to reaching more satisfactory results [4].

In this context, to prevent diarrhoea among young children, all possible carers should be involved, especially mothers, as these are usually responsible for the routine care of the child. For this, it is necessary that the mothers have knowledge about preventive actions, and also are able to carry them out with success; in other words, to improve their self-efficacy [5] [6]. Considering the importance of promotion of self-efficacy, a study carried out in Fortaleza has prepared and validated an educational video with the intention of stressing some measures of care to be adopted by mothers in their daily activities, to improve their self-efficacy to prevent diarrhoea in young children [7]. This technology is an important tool for health education, as it encourages the mother, boosting her confidence, as the woman is positively influenced by what she hears from other people, and when she sees other similar people also successfully carrying out certain tasks [8].

Due to this fact, there is a need to check the impact of the educational video for the prevention of diarrhoea in young children. It is expected that this strategy of health education may not only boost the self-efficacy of the mothers, but also guide the nursing professional to draw up a care plan for diarrhoea prevention in young children. Hence, this study aimed to compare the maternal self-efficacy scores, between the intervention and control groups, according to social, demographic and sanitary characteristics.

\section{Method}

\subsection{Design and Sample}

This is a randomised clinical trial conducted in a Primary Health Care Center (Unidade de Atenção Primáriaem Saúde-UAPS) in an area from Fortaleza, Ceará, Brazil, with 41,971 children under five years old. In 2012, this area had the highest number of notified diarrhoea cases: 5726 in all, of which 2172 (37.9\%) enrolled children under 5 yo [9] [10].

The study population consists of mothers of children registered at the UAPS. The inclusion criteria were: mothers with at least one child aged under 5 yo, being monitored at the UAPS and resident in the neighbourhoods established for the study. The exclusion criteria were: mothers with any kind of cognitive limitation that could compromise their participation in educational intervention or answering the scale, and those that did not have a telephone number for contact. Using these criteria initially 180 mothers were eligible for the study, being 90 mothers from the Intervention Group (IG) and 90 from the Control Group (CG) (Figure 1).

The groups were composed by cluster randomisation. Thus, a draw was made for a decision about the allocation of each district to one of the groups, so that the mothers resident in Neighbourhood A were placed in the CG and those from Neighbourhood B in IG. The selection of the mothers within each group was made by convenience, and the recruitment of the participations were made by invitation from the health community agents, with their appearance at the UAPS on set days, different days for the two groups.

\subsection{Measures}

For data collection, two different instruments were used: the Scale of Maternal Self-Efficacy for Prevention of Diarrhoea in Young Children (EAPDI) [11], and a socio-demographic form that addressed the demographic profile, social and economic conditions, and sanitary conditions [7]. The EAPDI has family hygiene and eating habits domains, with 15 and 9 items respectively, and with answers on a scale ranging from 1 (fully disagree) to 5 (fully agree), where the total scores on the scale could range from 24 to 120 scores. Here we stress that the EAPDI had a Content Validity Index (CVI) of 0.96 and a Cronbach alpha coefficient of 0.84 [11]. 


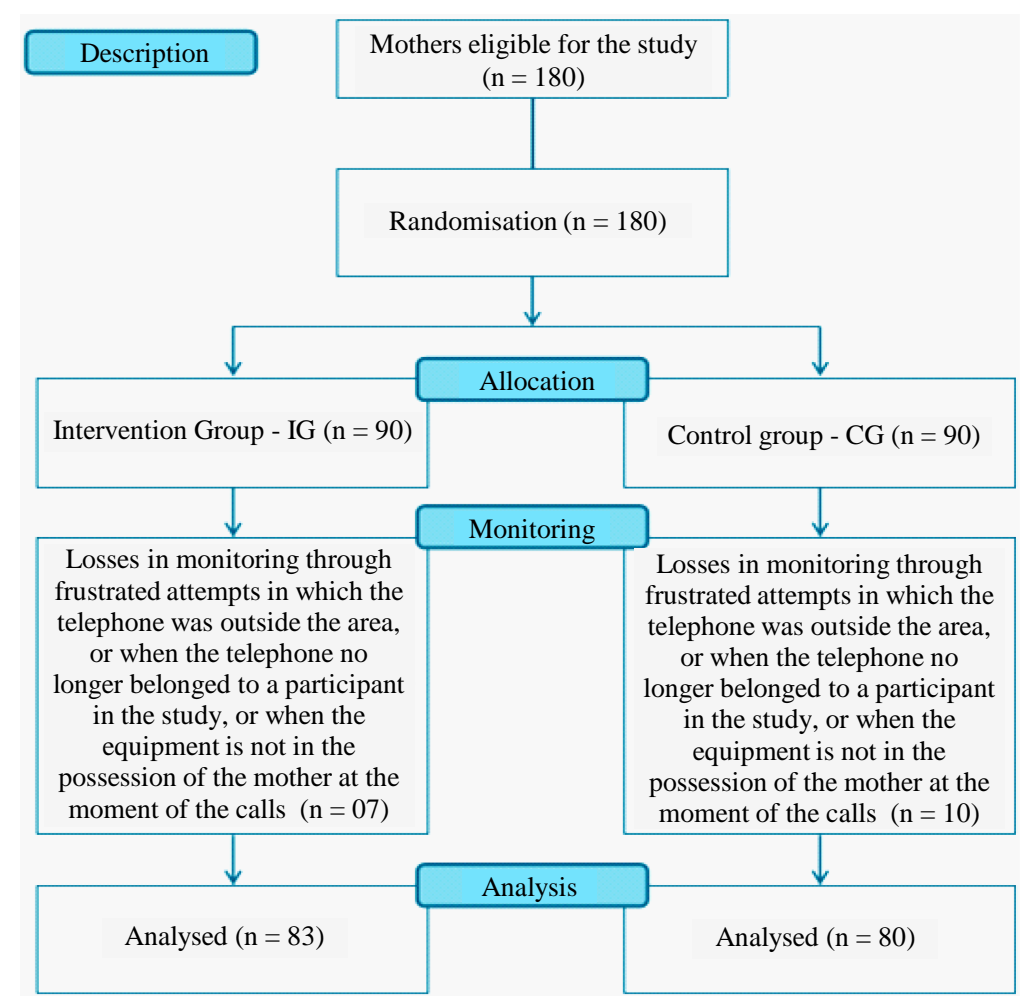

Figure 1. Flowchart of study participants. Fortaleza, Ceará, Brazil, 2014.

The data was collected in two stages, in IG and CG at the same time: the zero moment (M0), with the application of EAPDI and the socio-demographic form; and Moment 1 (M1), was the application of the EAPDI by telephone, two months after the first application. The instruments were applied by a trained team, that did not know which mothers belonged to which group (control group and intervention group).

The educational video "Diarrhoea in young children: you can prevent it" [12], with a total playing time of 16 minutes, was shown to the mothers from IG, in a reserved room at UAPS, with a portable DVD unit and a 21inch television, for no more than ten spectators per session, without additional guidance related to diarrhoea in young children, given by any of the researchers.

\subsection{Analytic Strategy}

The student t-test was used for independent data, for comparison of the means for the two groups considered, within each moment, and also the student t-test for dependent data to compare the means for each group, between the two moments considered, M0 and M1. A significance level of 5\% was set.

It was obtained informed consent from all the study participants of the study. The study was approved by the Ethics Committee of the Federal University of Ceara, under Protocol No.106/2012.

\section{Results}

According to Table 1, for the control group, the maternal self-efficacy for the prevention of diarrhoea in young children has not shown any statistically significant difference between M0 (101.1) and M1 (103.3) ( $p=0.115)$, while in the case of the intervention group the mean at M1 (109.8) was higher than that for M0 (106.6) $(\mathrm{p}=$ 0.042). This increase in the mean for the intervention group was due mainly to the participation of the age bracket of people 35 years old or more $(p=0.024)$, women with a higher educational level $(p=0.017)$ and those who are not homemakers $(\mathrm{p}=0.030)$. There was also evidence of a higher mean at M0 for women with a partner ( $p=0.054)$ and at M1 for women living with four or five people in the household ( $p=0.056)$.

In Table 2, the sanitary characteristics mostly also have an influence on maternal self-efficacy for the prevention of diarrhoea in young children. In this intervention group, on controlling sanitary characteristics, the mean 
Table 1. Comparison of means of the scale between the groups, according to the moment and to social and demographic characteristics (Fortaleza, Ceará, Brazil, 2013).

\begin{tabular}{|c|c|c|c|c|c|c|c|c|c|c|}
\hline \multirow{3}{*}{ Variables } & \multicolumn{4}{|c|}{ M0—UAPS } & \multicolumn{6}{|c|}{ M1 -2 months } \\
\hline & \multicolumn{2}{|c|}{ Control } & \multicolumn{2}{|c|}{ Intervention } & \multirow[b]{2}{*}{$\mathrm{p}^{(3)}$} & \multicolumn{2}{|c|}{ Control } & \multicolumn{2}{|c|}{ Intervention } & \multirow[b]{2}{*}{$\mathrm{p}^{(3)}$} \\
\hline & Mean & \pm SEM & Mean & \pm SEM & & Mean & \pm SEM & Mean & \pm SEM & \\
\hline EAPDI & 101.1 & 1.0 & & & & 103.3 & 0.9 & & & $0.115^{(1}$ \\
\hline EAPDI & & & 106.6 & 1.1 & & & & 109.8 & 1.1 & $0.042^{(2}$ \\
\hline \multicolumn{11}{|l|}{ Age Bracket } \\
\hline Up to 19 & 95.6 & 1.7 & 99.8 & 2.3 & 0.303 & 104.4 & 3.7 & 106.0 & 3.0 & 0.737 \\
\hline $20-34$ & 100.8 & 1.2 & 103.4 & 1.1 & 0.138 & 106.9 & 1.3 & 109.3 & 1.3 & 0.223 \\
\hline$\geq 35$ & 104.3 & 2.2 & 105.8 & 2.2 & 0.620 & 106.7 & 2.5 & 113.6 & 1.4 & 0.024 \\
\hline \multicolumn{11}{|l|}{ Marital Status } \\
\hline With Partner & 100.1 & 1.3 & 103.6 & 1.1 & 0.054 & 105.8 & 1.5 & 109.5 & 1.2 & 0.066 \\
\hline Without Partner & 102.6 & 1.5 & 102.6 & 1.8 & 0.987 & 107.7 & 1.6 & 110.3 & 1.88 & 0.302 \\
\hline \multicolumn{11}{|l|}{ Educational Level } \\
\hline Elementary & 105.1 & 2.2 & 103.3 & 1.7 & 0.540 & 109.2 & 2.5 & 107.3 & 2.2 & 0.588 \\
\hline High School & 104.3 & 1.7 & 106.3 & 1.7 & 0.441 & 103.9 & 1.8 & 110.7 & 1.99 & 0.017 \\
\hline \multicolumn{11}{|l|}{ Occupation } \\
\hline Homemaker & 101.2 & 1.1 & 103.6 & 1.0 & 0.133 & 107.7 & 1.2 & 109.8 & 1.2 & 0.253 \\
\hline Other & 100.6 & 2.3 & 102.6 & 2.0 & 0.523 & 103.1 & 2.3 & 109.8 & 1.8 & 0.030 \\
\hline \multicolumn{11}{|c|}{ Number of People in Household } \\
\hline Up to 3 & 101.9 & 1.7 & 103.8 & 1.5 & 0.450 & 107.2 & 2.1 & 110.2 & 1.8 & 0.307 \\
\hline $4-5$ & 100.3 & 1.4 & 103.2 & 1.4 & 0.172 & 105.4 & 1.6 & 109.9 & 1.4 & 0.056 \\
\hline $6-11$ & 101.9 & 2.4 & 102.4 & 2.3 & 0.880 & 109.1 & 2.0 & 108.8 & 2.5 & 0.941 \\
\hline \multicolumn{11}{|c|}{ Income in National Minimum Wages (MWg) } \\
\hline Up to $1 \mathrm{MWg}$ & 101.5 & 1.3 & 103.7 & 1.3 & 0.245 & 107.2 & 1.6 & 110.0 & 1.5 & 0.227 \\
\hline$\geq 1 \mathrm{MWg}$ & 101.0 & 1.5 & 102.9 & 1.3 & 0.373 & 106.3 & 1.5 & 109.7 & 1.4 & 0.121 \\
\hline
\end{tabular}

SEM = Standard Error of the Mean; $\mathrm{p}^{(1)}$ and $\mathrm{p}^{(2)}$ : t-student test for independent data; $\mathrm{p}^{(3)}$ : $\mathrm{t}$-student test for dependent data. $\mathrm{p}^{(1)}=$ comparison of the means for the control group between the moments, M0 and M1; $\mathrm{p}^{(2)}=$ comparison of means for the intervention group, between M0 and $\mathrm{M} 1$; $\mathrm{p}^{(3)}=$ comparison of means between the control and intervention groups, at moments M0 and M1.

at moment M1 was greater in women whose home was not constructed with bricks and mortar ( $p=0.014)$, had public refuse collection ( $\mathrm{p}=0.045$ ), where the origin of the water supply was through the public piped system ( $\mathrm{p}$ $=0.035)$, the water that the child drinks is of mineral origin $(\mathrm{p}=0.040)$ and that had a public sewerage network in place $(\mathrm{p}=0.013)$.

Thus, we deduce that the analysis of the impact of the educational video "Diarrhoea in young children: you can prevent it", considering the social, demographic and sanitary characteristics, has an influence on maternal self-efficacy, as after the intervention, in the IG the mean scores of self-efficacy were higher than in the CG and, in addition, they increased in M1 with statistical significance for most of the social and demographic variables, and for all sanitary variables.

\section{Discussion}

Self-efficacy revealed the trust that a person has in execution of a certain action and, for this reason, it becomes necessary that this has a high value so that the individual may feel capable and motivated to carry out actions that promote their health. Even though self-efficacy is a personal characteristic, it is know that educational interventions that promote health are able to empower the person in his or her own self-care and raise his or her self-efficacy through an increase in knowledge and trust, through the social, demographic and sanitary conditions. 
Table 2. Comparison of means of the scale within the groups, according to the moment and to sanitary characteristics (Fortaleza, Ceará, Brazil, 2013).

\begin{tabular}{|c|c|c|c|c|c|c|c|c|c|c|}
\hline \multirow{3}{*}{ Variables } & \multicolumn{4}{|c|}{ M0_UAPS } & \multicolumn{6}{|c|}{ M1-2 months } \\
\hline & \multicolumn{2}{|c|}{ Control } & \multicolumn{2}{|c|}{ Intervention } & \multirow[b]{2}{*}{$\mathrm{p}^{(1)}$} & \multicolumn{2}{|c|}{ Control } & \multicolumn{2}{|c|}{ Intervention } & \multirow[b]{2}{*}{$\mathrm{p}^{(1)}$} \\
\hline & Mean & \pm SEM & Mean & \pm SEM & & Mean & \pm SEM & Mean & \pm SEM & \\
\hline \multicolumn{11}{|l|}{ Type of House } \\
\hline Bricks and Mortar & 101.0 & 1.2 & 103.0 & 1.1 & 0.273 & 107.5 & 1.3 & 109.1 & 1.2 & 0.392 \\
\hline Others & 101.1 & 1.5 & 104.0 & 1.6 & 0.225 & 104.6 & 1.9 & 111.4 & 1.8 & 0.014 \\
\hline \multicolumn{11}{|l|}{ Floor of House } \\
\hline Ceramic & 101.4 & 1.9 & 102.7 & 1.89 & 0.635 & 106.9 & 1.8 & 111.5 & 1.9 & 0.102 \\
\hline Others & 100.9 & 1.23 & 103.5 & 1.1 & 0.127 & 106.5 & 1.3 & 109.2 & 1.2 & 0.158 \\
\hline \multicolumn{11}{|l|}{ Refuse Collection } \\
\hline Public & 100.9 & 1.0 & 103.5 & 0.9 & 0.069 & 106.4 & 1.1 & 109.6 & 1.0 & 0.045 \\
\hline Others & 112.0 & - & 96.0 & 2.6 & 0.094 & 120.0 & - & 114.3 & 2.8 & 0.425 \\
\hline \multicolumn{11}{|c|}{ Origin of the Water That Supplies the House } \\
\hline Piped-Public & 101.2 & 1.0 & 103.5 & 0.9 & 0.117 & 106.5 & 1.1 & 109.8 & 1.0 & 0.035 \\
\hline Others & 94.0 & 3.0 & 97.6 & 0.8 & 0.240 & 116.0 & - & 109.0 & 6.6 & 0.652 \\
\hline \multicolumn{11}{|c|}{ Origin of the Water That the Child Drinks } \\
\hline Mineral & 100.8 & 1.1 & 103.2 & 1.0 & 0.143 & 107.1 & 1.2 & 110.6 & 1.1 & 0.040 \\
\hline Others & 102.3 & 2.2 & 103.6 & 2.0 & 0.706 & 103.9 & 2.9 & 107.5 & 2.3 & 0.350 \\
\hline \multicolumn{11}{|c|}{ Treatment of the Child's Water } \\
\hline Yes & 104.7 & 2.8 & 109.9 & 1.9 & 0.177 & 109.0 & 2.6 & 114.4 & 1.3 & 0.103 \\
\hline No & 100.3 & 1.0 & 102.2 & 1.0 & 0.211 & 106.2 & 1.2 & 109.1 & 1.1 & 0.098 \\
\hline \multicolumn{11}{|l|}{ Sewage } \\
\hline Public & 99.7 & 2.7 & 102.4 & 2.6 & 0.494 & 105.9 & 2.8 & 114.6 & 1.6 & 0.013 \\
\hline Cesspool or Other & 101.4 & 1.1 & 103.5 & 1.0 & 0.160 & 106.8 & 1.2 & 108.7 & 1.2 & 0.270 \\
\hline
\end{tabular}

SEM = Standard Error of the Mean; $\mathrm{p}^{(1)}=$ comparison of means between the control and the intervention groups, at the moments M0 and M1.

In this study, the educational video has had a significant influence on the larger self-efficacy in preventing diarrhoea among young children in the case of mothers with the following social and demographic characteristics: age of 35 years or more; high-school education; living with a partner; not being homemakers; and residing in a household with 4 or 5 people.

In an observational study which analysed deaths from diarrhoea among children aged under 5 years over a period of 20 years, it was observed that the deaths were most common among children of mothers aged between 20 and 29, and with less than eight years of schooling [13]. Confirming the findings, a cross-sectional study conducted in the city of Picos, State of Piauí, Brazil, has associated younger age and less schooling of the carer with the occurrence of diarrhoea in children [14]. One can therefore reach the conclusion that is due to less knowledge and experience, and therefore self-efficacy that the younger mothers have over the prevention of diarrhoea; indeed, it is well known that the expected self-efficacy can be improved based on prior positive experiences [15].

Therefore, considering the relationship as inversely proportional, meaning that mothers with more advanced age and a higher level of schooling should present higher scores when it comes to maternal self-efficacy, we see that this study confirms the findings as previously mentioned. On the other hand, it is also valid to highlight that there are some disagreements about educational level, considering that a research study in the city of Manaus, Amazonas, North of Brazil did not find any association between this and the occurrence of intestinal parasitoses [16].

In relation to occupation, the research study carried out in the city of Picos, Piauí, Brazil, which proposed to 
get to know the profiles of the children admitted to hospital with diarrhoea, showed that the overwhelming majority of the people taking care of the children were mothers and homemakers [14]. Considering that the mothers in this study with greatest self-efficacy normally worked outside the home, had a partner and lived in a household with 4 or 5 people, we deduce that the coexistence with other people can have a positive influence on behaviour and actions of the mothers, in taking care of children in order to prevent diarrhoea; as the theory of selfefficacy considers verbal persuasion, support and motivation of people close by as favouring participation and changes of behaviour [15].

Cross-sectional study conducted in Jatinegara, Eastern District of Jakarta, Indonesia, enrolling 274 children between 12 and 50 months old, found that those who belong to families with 6 people or more were 2.3 times more likely to experience diarrhoea [17].

A research study in Porto Alegre, South of Brazil investigated paternal involvement in care for children, and showed that many fathers said they carry out regular or eventual care activities with the child, and participate in the decisions together with the mother about how the child should be cared for, and also showed a concern with the prevention and treatment of diseases [18]. This shows the presence of the father in caring for the children, and also suggests the possibility of paternal influence over maternal self-efficacy.

In relation to family income, even though this variable has not shown significance in this study, it is worth pointing out that children from poor families are often said to be the population with the greatest risk of exposure to inappropriate water and sanitation, and their carers are less likely to follow healthy patterns of behaviour such as washing one's hands or safe elimination of the waste, behaviour patterns that could reduce the risk of exposure to infectious agents [19]. Thus, considering that people's behaviour is a consequence of their self-efficacy, we conclude that mothers from poor families need further encouragement in relation to maternal self-efficacy to prevent diarrhoea among young children.

In regards to sanitary characteristics, we see that most mothers have also shown significant tendency to have the highest scores of material self-efficacy in the intervention group, only two months after educational activities (M1). This means that the understanding that the risk of diarrhoea among their young children is lower considering mothers who live in houses built with other construction materials, with public refuse collection, public piped water supplying the house, the children drinking mineral water and the presence of a public sewage system.

About the type of house, they were constructed with other materials (mud huts, mixed construction or in brick without mortar) had statistical significance, a fact which is not confirmed by other studies. In a cross-sectional study, conducted in the Guarulhos, São Paulo, Southeast of Brazil, it was possible to identify that the construction of housing units in materials other than bricks is considered a risk factor for diarrhoea among the children considered [3].

A social and environmental research study and parasitological survey with the population of a community in the city of Manaus, Amazonas, North of Brazil has identified a greater prevalence of intestinal parasites among people living in houses of wooden construction. On the other hand, when the house was mixed construction, part wood and part stonemasonry, we see a protection factor for intestinal parasites, as also for worms (helminthoses) and protozooses [16].

Likewise, a group of children from Misiones, Argentina, with the highest occurrence of parasites residing in wood and metal houses with dirt floors [20].

Considering refuse collection, the public variable was associated to self-efficacy, proving to be a factor that can prevent diarrhoea among young children. Even though a study of the case-serial type about an outbreak of diarrhoea in children has confirmed that half the families interviewed had access to the public refuse collection system [21] and another research study about environmental diagnosis had shown that $87.2 \%$ of interviewees also had it, there was a major accumulation of litter in peridomiciliar areas [16].

Due to this fact and in spite of the presence of public refuse collection, it is important that the population is made aware, to take care of the environment where they live, considering that the scattering of waste around the houses is an element that indicates inappropriate sanitary practices and also contributes to the vectors' proliferation that spread infectious diseases [16].

Concerning the origin of the water supplying the house, and the water that the child drinks, the variables of piped and mineral water, respectively, have shown a capacity to predict maternal self-efficacy for the diarrhoea prevention in young children. To a certain extent, these results are similar to those found in a study that associated the prevalence of intestinal parasites with the origin of the water, as there was a higher number of positive 
results for intestinal parasites in people who used water from other sources, other than the piped and public water distribution system [16].

A cross-sectional study developed in the Canindé, Ceará, Northeast of Brazil with 56 families benefiting from cisterns, it was observed that, before these were constructed, 21 (37.5\%) of participating families made use of water from water holes for human consumption, and the illnesses that most commonly afflicted these children were diarrhoea and worms, respectively with 40 (71.4\%) and 31 (55.4\%) cases [22].

In contrast, a study carried out in Guarulhos, São Paulo, did not find any significant association between access to water and occurrence of diarrhoea, possibly because nearly all the population had access to the water supply network. However, some community agents for health have reported that many families used water from the public network and also from wells and streams at the same time, due to the frequent interruptions of the water supply; this is a factor that has contributed to the occurrence of diarrhoea through placing water in household tanks of precarious quality and lacking adequate hygiene [3].

It was not found significant association between diarrhea and water source and that is used for drinking, which could be explained by the fact that the majority of respondents boil water before consumption [17].

The kind of public sewage system, due to its connection with greater self-efficacy, seems to be a protective factor for diarrhoea in young children. In agreement, a survey conducted in Manaus, State of Amazonas, says that the spilling of sewage in the open has proved to be a risk factor for intestinal parasites [16].

However, another study has not confirmed any relationship between the occurrence of diarrhoea and the lack of a public sewage collection network, but when this variable has been associated to the type of housing, there was the identification of a fifteenfold increase in the risk of occurrence of diarrhoea for children living in houses where these two conditions were present [3].

The social, demographic and sanitary characteristics are, indeed, closely related to maternal self-efficacy for the diarrhoea prevention among young children. Thus, there is evidence of the need to develop strategies for health education which are able to empower the mothers to take care of their children, as also intersectorial actions for basic sanitation, so as to improve the general living conditions of the population, with a resulting decline in the number of diarrhoea cases.

\section{Conclusions}

This study revealed that the video "Diarrhoea in young children: you can prevent it" is an efficient strategy, so that it has been possible to perceive statistical significance for the increase in maternal self-efficacy in the prevention of diarrhoea among young children, in the intervention group, especially two months after the execution of educational activities, showing that health education activities can still increase the self-efficacy scores.

Thus, the relationship between social, demographic and sanitary characteristics of the mothers with their selfefficacy means that it is first up to the nurse to identify the context in which the mothers and children are inserted, to prepare strategies to prevent diarrhoea among young children, individualised and also in line with the reality of the individuals affected.

In addition, it is expected that the educational intervention, particularly the video used in this research, is a facilitator of the assistance provided by the nurse, especially those who are active in the Family Health Strategy, being able to make the practice of health education more dynamic and interactive, so as to empower the family and also collectivity in an efficient manner.

On the other hand, the study limitations were the short period of assessment of maternal self-efficacy and also the difficulty to re-establish contact with the mothers by telephone.

\section{Acknowledgements}

We would like to thank all participants in the study.

\section{References}

[1] World Health Organization (2009) Global Health Risks: Mortality and Burden of Disease Attributable to Selected Major Risks. World Health Organization, Geneva.

[2] Brasil (2010) Sistema de Planejamentodo SUS: Umaconstruçãocoletiva: Plano Nacional de Saúde (PNS) 2008/20092011. Ministério da Saúde, Brasília.

[3] Paz, M.G.A., Almeida, M.F. and Gunther, W.M.R. (2012) Diarrhea in Children and Sanitation and Housing Conditions 
in Periurban Areas in the City of Guarulhos, SP. Revista Brasileira de Epidemiologia, 15, 188-197. http://dx.doi.org/10.1590/S1415-790X2012000100017

[4] Freitas, C.A.S.L., Brito, M.C.C., Pinheiro, A.K.B., Silva, M.J., Dias, M.S.A. and Gubert, F.A. (2010) Perceptions of Nursing Students about the Health Promotion: Exploratory-Descriptive Study. Online Brazilian Journal of Nursing, 9. http://www.objnursing.uff.br/index.php/nursing/article/view/j.1676-4285.2010.2819

[5] Bandura, A. (2006) Toward a Psychology of Human Agency. Perspectives on Psychological Science, 1, 164-180. http://dx.doi.org/10.1111/j.1745-6916.2006.00011.x

[6] Lopes, T.C., Chaves, A.F.L., Joventino, E.S., Rocha, R.S., Castelo, A.R.P. and Oriá, M.O.B. (2013) Assessment of the Maternal Self-Efficacy for Child Diarrhea Prevention. Revista da Rede de Enfermagem do Nordeste, 14, 1103-1111.

[7] Joventino, E.S. (2010) Desenvolvimento de escala para mensurar a autoeficácia maternanaprevenção da diarreiainfantil. 2010. Dissertação, Universidade Federal do Ceará, Fortaleza, Brasil.

[8] Eidman, C.K. (2011) Enhancing Breastfeeding Self-Efficacy through Prenatal Education. Master’s Thesis, St. Catherine University, Minneapolis, Minnesota, EUA. http://sophia.stkate.edu/ma_nursing/31

[9] Fortaleza (2013) Consolidado das notificações de casos de diarreiaagudapor Secretaria Executiva Regional. Secretaria Municipal de Saúde, Célula de Vigilância Epidemiológica/CIEVS/SIMDA, Fortaleza. http://tc1.sms.fortaleza.ce.gov.br/simda/notifica/graficoSerano=2012\&ser=\&agravo=A09

[10] Instituto Brasileiro de Geografia e Estatística (2010) Distribuição da populaçãoporsexo, segundoosgrupos de idadeCenso 2010. http://www.censo2010.ibge.gov.br/sinopse/index.php?dados=26\&uf=23\#topo piramide

[11] Joventino, E.S., Ximenes, L.B., Almeida, P.C. and Oriá, M.O.B. (2013) The Maternal Self-Efficacy Scale for Preventing Early Childhood Diarrhea: Validity and Reliability. Public Health Nursing, 30, 150-158. http://dx.doi.org/10.1111/j.1525-1446.2012.01042.x

[12] Joventino, E.S. (2013) Elaboração e validação de vídeo educativo para promoção da autoeficácia maternal na prevenção da diarréia infantil. Tese, Universidade Federal do Ceará, Fortaleza.

[13] Melli, L.C.F.L. and Waldman, E.A. (2011) Temporal Trends and Inequality in Under-5 Mortality from Diarrhea. Archivos de Pediatría del Uruguay, 82, 39-46. http://www.scielo.edu.uy/pdf/adp/v82n1/v82n1a10.pdf

[14] Sousa, G.R.S., Oliveira, E.A.R., Lima, L.H.O., Silva, A.K.A., Formiga, L.M.F. and Rocha, S.S. (2013) Profile of Children with Diarrhea in a Public Hospital. Revista de Enfermagem da UFPI, 2, 34-39.

[15] Bandura, A. (1977) Self-Efficacy: Toward a Unifying Theory of Behavioral Change. Psychological Review, 84, 191215. http://dx.doi.org/10.1037/0033-295X.84.2.191

[16] Visser, S., Giatti, L.L., Carvalho, R.A.C. and Guerreiro J.C.H. (2011) Study of the Association between Socio-Environmental Factors and the Prevalence of Intestinal Parasitosis in the Suburbs of the City of Manaus in the State of Amazonas, Brazil. Ciência \& Saúde Coletiva, 16, 3481-3492.

[17] Agustina, R., Sari, T.P., Satroamidjojo, S., Bovee-Oudenhoven, I.M.J., Feskens, E.J.M. and Kok, F.J. (2013) Association of Food-Hygiene Practices and Diarrhea Prevalence among Indonesian Young Children from Low Socioeconomic Urban Areas. BMC Public Health, 13, 1-12. http://dx.doi.org/10.1186/1471-2458-13-977

[18] Gonçalves, T.R., Guimarães, L.E., Silva, M.R., Lopes, R.C.S. and Piccinini, C.A. (2013) Fatherhood Experience in Infant's Third Month. Psicologia: Reflexão e Crítica, 26, 599-608.

http://www.scielo.br/scielo.php?script=sci_arttext\&pid=S0102-79722013000300020 http://dx.doi.org/10.1590/S0102-79722013000300020

[19] Barros, F.C., Victora, C.G., Scherpbier, R. and Gwatkin, D. (2010) Socioeconomic Inequities in the Health and Nutrition of Children in Low/Middle Income Countries. Revista de Saúde Pública, 44, 1-16. http://dx.doi.org/10.1590/S0034-89102010000100001

[20] Zonta, M.L., Oyhenart, E.E. and Navone, G.T. (2014) Socio-Environmental Variables Associated with Malnutrition and Intestinal Parasitoses in the Child Population of Misiones, Argentina. American Journal of Human Biology, 26, 609-616. http://dx.doi.org/10.1002/ajhb.22570

[21] Araújo, T.M.E., Dantas, J.M., Carvalho, C.E.F. and Costa, M.A.O. (2010) Outbreak of Diarrhea by Rotavirus in Bom Jesus City, Piauí State. Ciência \& Saúde Coletiva, 15, 1039-1046.

[22] Joventino, E.S., Silva, S.F., Rogerio, R.F., Freitas, G.L., Ximenes, L.B. and Moura, E.R.F. (2010) Behavior of Childhood Diarrhea before and after Consumption of Rainwater in the City of Semi-Arid of Brazil. Texto \& Contexto-Enfermagem, 19, 691-699. 
Scientific Research Publishing (SCIRP) is one of the largest Open Access journal publishers. It is currently publishing more than 200 open access, online, peer-reviewed journals covering a wide range of academic disciplines. SCIRP serves the worldwide academic communities and contributes to the progress and application of science with its publication.

Other selected journals from SCIRP are listed as below. Submit your manuscript to us via either submit@scirp.org or Online Submission Portal.
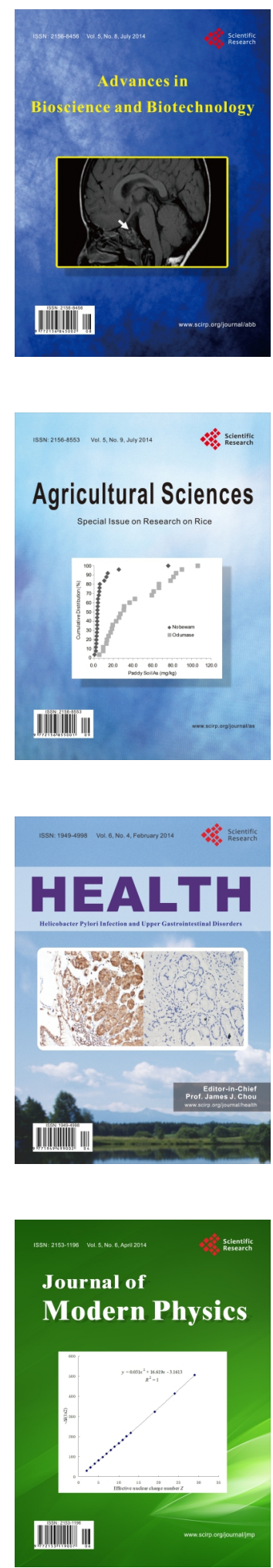
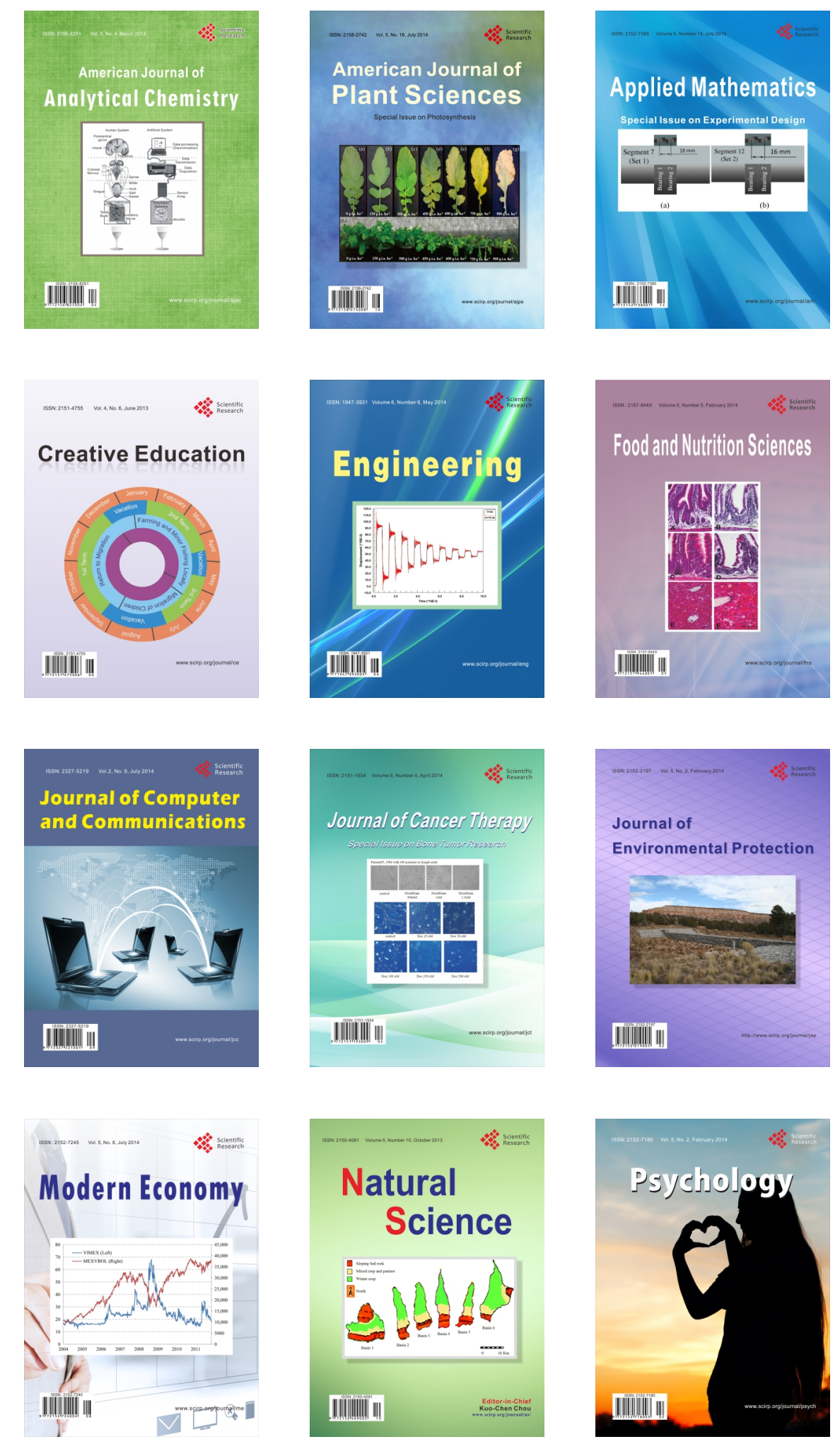